\title{
A new approach to firm evaluation
}

\author{
Erik M. Vermeulen*, Jaap Spronk** and Nico van der Wijst*** \\ Erasmus University Rotterdam, Department of Finance/Tinbergen Institute, \\ P.O. Box 1738, 3000 DR Rotterdam, The Netherlands
}

\begin{abstract}
In this paper, a method is developed to evaluate firms on the basis of the risks they face. In accordance with the multi-factor method, risk is represented as a vector of sensitivities to unexpected changes of risk factors. Subsequently, the sensitivities themselves are related to firm characteristics.

In addition, an application of the method to interfirm comparison is presented. This application is illustrated by a numerical example based on estimates concerning real data. Apart from this application, some other possible future applications are mentioned. Finally, some decision support tools are presented which may enhance the usefulness of the method in practice.
\end{abstract}

Keywords: Decision support systems, firm evaluation, interfirm comparison, multifactor method, risk analysis.

\section{Introduction}

Firm evaluation is an important issue not only for the firm itself, but also for a.o. bankers, accountants and consultants. Such an evaluation is often based on interfirm comparisons in which the firm is compared with its average competitor. The main problem for scientists is the model behind the evaluation. We agree with Lev [9, p. 149], who states that most of these models are somewhat lacking in theoretical background. In this paper we propose a framework to evaluate the risks faced by the firm.

The proposed framework is similar to one used to assess the riskiness of security portfolios. In this so-called multi-factor method, risk is viewed as a multi-dimensional concept. The unexpected return on an asset is assumed to be dependent both on unexpected changes of exogenous factors and on the sensitivities for these unexpected changes of factors. Examples of such factors

* Tinbergen Institute and Department of Finance of Erasmus University Rotterdam and EIM Small Business Research and Consultancy, Zoetermeer.

** Department of Finance, Erasmus University Rotterdam.

*** EIM Small Business Research and Consultancy, Zoetermeer. 
are the interest rate and the oil price. Here, the sensitivities give an indication of the risks of the assets, conditional on the unexpected changes of the factors.

The same framework of risk analysis can be applied to firm evaluation. For example, the unexpected change of the cash flow of a firm may be related to unexpected changes of exogenous factors and sensitivities to these changes. The vector of sensitivities is called the risk profile of the firm. By taking firm characteristics into account as well, the method can be refined further, because the sensitivities are likely to be related to firm characteristics. For instance, a high interest rate sensitivity may, to a large extent, be explained by a high debt level. This approach results in a risk analysis method that indicates what the risks are (i.e. those sensitivities which are relatively high) and what can be done to reduce them (i.e. try to change those firm characteristics which influence these sensitivities). An advantage of this method is its prospective character: firms are not evaluated on their behavior in the past but on their future position.

The aim of this paper is, firstly, to present the underlying theoretical model to evaluate firms, and, secondly, to show some practical applications of the method. These applications are illustrated by numerical examples obtained from an empirical model, which corresponds with the above mentioned theoretical model. In this paper, we also present this empirical model and the obtained estimation results. However, the reader should bear in mind that these estimation results mainly serve to illustrate the applications. The econometric validity of this and similar models is still being investigated. It is clear that the success of the model depends heavily on the availability of data.

The organization of this paper is as follows. Section 2 deals with the theoretical model underlying the risk analysis method, while the empirical model is described in section 3. Subsequently, section 4 presents the contents of the empirical model, and section 5 gives a description of the data used to estimate the model. The estimation results are presented in section 6 and an application concerning interfirm comparison is shown in section 7. Section 8 describes some alternative applications and section 9 discusses some decision support tools, which may enhance the applicability of the model in practice. The main conclusions are given in section 10 .

\section{A theoretical model for risk analysis}

In this paper, we aim to compare firms on the basis of their risk profiles. For this purpose, it is necessary to construct a model that provides insight into the risks firms face. Recently, for security analysis the so-called multi-factor has been developed. In our risk analysis of firms we will adapt this approach by constructing a similar multi-factor model for firms. In this section, we will first present the multi-factor portfolio model and then its analogue for firms.

In the multi-factor portfolio model, risk is considered as a multi-dimensional concept. Securities are no longer valued on their mean-variance characteristics, but 
through their sensitivities to unexpected changes of exogenous economic factors. Thus, the variances of and the covariances between the exogenous factors are taken into account indirectly. In this view the return on a stock of firm $n$ can be written as

$$
\tilde{R}_{n t}=E\left(\tilde{R}_{n t}\right)+b_{1 n} \Delta \tilde{f}_{1 t}+\ldots+b_{k n} \Delta \tilde{f}_{k t}+\tilde{\epsilon}_{n t}
$$

Here, $\tilde{R}_{n t}$ denotes the random return on stock $n$ at time $t, E\left(\tilde{R}_{n t}\right)$ is the expected return on the stock, $b_{i n}$ stands for the sensitivity of stock $n$ to an unexpected change in environmental factor $i, \Delta \tilde{f}_{i t}$ denotes an unexpected change of factor $i$ and $\tilde{\epsilon}_{n t}$ is an error term. Note that the sensitivities, $b_{i n}, i=1, \ldots, k$, are implicitly assumed to be constant over time.

Applying the same methodology to the uncertain values of performance measures of firms, ${ }^{1}$ we get:

$$
\tilde{R}_{n t}=E\left(\tilde{R}_{n t}\right)+b_{1 n t} \Delta \tilde{f}_{1 t}+\ldots+b_{k n t} \Delta \tilde{f}_{k t}+\tilde{\epsilon}_{n t}
$$

In this expression $n$ denotes the firm and $t$ time, $\tilde{R}_{n t}$ is the uncertain value of a performance measure of firm $n$ at some future time $t, E\left(\tilde{R}_{n t}\right)$ is the expected value of the performance measure, $b_{\text {int }}$ is the sensitivity to an unexpected change in environmental factor $i$ at time $t, \Delta \tilde{f}_{i t}$ the unexpected change of factor $i$ and $\tilde{\epsilon}_{n t}$ is an error term. Note that the sensitivity $b_{\text {int }}$ represents the influence of a marginal unexpected change of the exogenous factor on the performance measure.

Next, the sensitivity to a factor is assumed to be explained by $m$ firm characteristics, ${ }^{2}$ i.e.:

$$
\tilde{b}_{i n t}=\gamma_{0 i}+f c_{1 n t} \cdot \gamma_{1 i}+\ldots+f c_{m n t} \cdot \gamma_{m i}+\tilde{\eta}_{i n t} \quad i=1, \ldots, k, t=1, \ldots, T
$$

In this expression, $\tilde{b}_{\text {int }}$ is the sensitivity to an unexpected change of exogenous factor $i$ at time $t, f c_{j n t}$ stands for the value of firm characteristic $j$ of firm $n$ at time $t$, and $\tilde{\eta}_{\text {int }}$ is an error term.

We implicitly assume $\partial b_{i n t} / \partial f c_{j n t}=\gamma_{j i}$, i.e. $\gamma_{j i}$ is the marginal changing influence of the firm characteristic $f c_{j n t}$ on the sensitivity $\tilde{b}_{\text {int }}$. Note also that we implicitly assume that all differences in sensitivities among firms can be explained by firm characteristics.

${ }^{1}$ Foster [5] as well as Lev [10] considered a similar kind of model using indexes as factor values. However, they did not take our next step, i.e. they did not try to explain sensitivities by firm characteristics. As a result, they were not able to pool the data and had to estimate relation (2.2) for each firm under consideration separately.

${ }^{2}$ Instead of explaining the sensitivities to factor changes, Van Gremsbergen [14] as well as Rosenberg and McKibben [11] explain the accounting and market beta in a similar way. 
Substitution of expression (2.3) into (2.2) leads to:

$$
\tilde{R}_{n t}=E\left(\tilde{R}_{n t}\right)+\sum_{i=1}^{k}\left(\gamma_{0 i}+\sum_{j=1}^{m} \gamma_{j i} \cdot f c_{j n t}\right) \cdot \Delta \tilde{f}_{i t}+\tilde{\nu}_{n t} \quad n=1, \ldots, N, t=1, \ldots, T
$$

In this expression, $k$ denotes the number of factors and $m$ the number of firm characteristics. Note that $\tilde{\nu}_{n t}=\tilde{\epsilon}_{n t}+\sum_{i=1}^{k} \tilde{\eta}_{i n t} \cdot \Delta \tilde{f}_{i t}$, hence the stochastic structure of $\tilde{\nu}_{n t}$ depends on the stochastic structure of $\tilde{\epsilon}_{n t}$ and $\tilde{\eta}_{\text {int }}$.

\section{Operationalisation of the model}

Given the theoretical model (2.4) we have to take account of the fact that in this kind of applications, data typically consist of yearly observations of firm characteristics instead of the marginal changes on which eq. (2.4) is based. Thus, we must work with yearly changes as an approximation for marginal changes. Moreover, the unexpected changes in exogenous factors as well as the expected value of the performance measure are not observed; only realized yearly changes are observed. Consequently, expression (2.4) has to be adapted.

Let us assume that the sensitivity for an expected change in factor value, i.e. $\left(E\left(\tilde{f}_{i t}\right)-f_{i, t-1}\right)$, is the same as for an unexpected change in factor value, i.e. $\left(\tilde{f}_{i t}-E\left(\tilde{f}_{i t}\right)\right)$, and hence: ${ }^{3}$

$$
E\left(\tilde{R}_{n t}\right)=R_{n, t-1}+\sum_{i=1}^{k} b_{i n t} \cdot\left(E\left(\tilde{f}_{i t}\right)-f_{i, t-1}\right)
$$

Furthermore, recalling that the unexpected change in factor value is defined as the realized factor value minus the expected change, i.e. $\Delta \tilde{f}_{i t} \equiv \tilde{f}_{i t}-E\left(\tilde{f}_{i t}\right)$, and substituting (3.1) into (2.4), leads to

$$
\tilde{R}_{n t}-R_{n t-1}=\sum_{i=1}^{k}\left(\gamma_{0 i}+\sum_{j=1}^{m} \gamma_{j i} \cdot f c_{j n t}\right) \cdot\left(\tilde{f}_{i t}-f_{i t-1}\right)+\tilde{\nu}_{n t} \quad n=1, \ldots, N, t=1, \ldots, T .
$$

${ }^{3}$ The same result can be obtained beginning from the following principal multi-factor model: $\tilde{R}_{n t}=b_{0 n t}+b_{1 n t} \cdot \tilde{f}_{1 t}+\ldots+b_{k n t} \cdot \tilde{f}_{k t}+\tilde{\epsilon}_{n t}$. However, it should be noted that this model is more restrictive than the model of expression (2.2). In expression (2.2), a linear relationship is assumed between unexpected performance and unexpected changes of factor values, whereas the relation mentioned above assumes a linear relationship between the level of performance and the level of factor values. 
The corresponding ex post empirical relation reads as follows

$$
R_{n t}-R_{n t-1}=\sum_{i=1}^{k}\left(\gamma_{0 i}+\sum_{j=1}^{m} \gamma_{j i} \cdot f c_{j n t}\right) \cdot\left(f_{i t}-f_{i t-1}\right)+\tilde{\nu}_{n t} \quad n=1, \ldots, N, t=1, \ldots, T
$$

where

$$
\tilde{\nu}_{n t}=\tilde{\epsilon}_{n t}+\sum_{i=1}^{k} \tilde{\eta}_{i n t} \cdot\left(f_{i t}-f_{i t-1}\right)
$$

In this expression $\left(R_{n t}-R_{n t-1}\right)$ is the realized change in the value of the performance measure of firm $n$ from $t-1$ to $t, f c_{j n t}$ is the $j$ th firm characteristic of firm $n$ at time $t$ and $\left(f_{i t}-f_{i t-1}\right)$ denotes the realized change in factor $i$ from $t-1$ to $t$.

The estimation procedure depends among things on the assumptions with respect to $\tilde{\epsilon}$ and $\tilde{\eta}$, and on the validity of these assumptions. We assume that $\tilde{\epsilon}$ is normally distributed and that its specifications are identical to those of the linear regression model. ${ }^{4}$ Concerning $\tilde{\eta}$, we join Van Gremsbergen [14] by assuming that $\tilde{\eta}_{i n t}=0$. As a result, the parameters $\hat{\gamma}_{j i}$ of expression (3.3) can be estimated using Ordinary Least Squares.

The estimated parameters $\hat{\gamma}_{j i}$ can be interpreted as the yearly change of a sensitivity caused by a yearly change of a firm characteristic. Next, the sensitivity of a firm to an exogenous factor can be calculated using expression (2.3)

$$
\hat{b}_{i n t}=\hat{\gamma}_{0 i}+f c_{1 n t} \cdot \hat{\gamma}_{1 i}+\ldots+f c_{m n t} \cdot \hat{\gamma}_{m i}
$$

This expression says that the sensitivity equals the sum of the products of the firm characteristics and the sensitivity changing influence of these characteristics.

Analogously, the covariance matrix of $\hat{b}_{\text {int }}$ can be computed as follows:

$$
\operatorname{COV}\left(\hat{b}_{i n t}\right)=\overline{f c}^{\mathrm{T}} \operatorname{COV}(\hat{\gamma}) \overline{f c}
$$

In this relation, $\mathrm{COV}$ stands for the covariance matrix, and $\overline{f c}$ for the vector $\left(1, f c_{1 n t}, \ldots, f c_{m n t}\right)$.

\section{The empirical contents of the model}

The next question is which economic quantities should be chosen as performance measures, risk factors and sensitivity determining firm characteristics.

\footnotetext{
${ }^{4}$ I.e. zero expected value, constant variance, no autocorrelation in the residuals and independence between the residual term and the independent variables.
} 
In order to answer this question, one could construct a micro-economic input/output model underlying the choice of the performance measure and the risk factors. In that case the input factors would be the level of capital and labour used by the firm, whereas the output would consist of a number of products produced by the firm. Uncertainty in the model is caused by the uncertain prices of the input and output factors. Hence, by the interest rate (the price of capital), the wage rate (the price of labour) and by the price of the products. Of course, the sensitivity to a price change, which is the influence of a price change on the performance of the firm, depends both on the level of capital and labour, and on the kind of capital and labour. ${ }^{5}$

A mathematical specification of this micro-economic model would go beyond the purpose of this paper, which is to provide an instrument to measure sensitivities and to show how these sensitivities can be used in practical applications. On the other hand, the risk factors and sensitivity determining firm characteristics have been chosen in accordance with the above mentioned literature.

In this paper, the cash flow and the wage costs flow serve as performance measures. The former is chosen, because it is a primary determinant of the firm's value, the latter, because it will be used in the example concerning interfirm comparison in section 7. As a result, expression (3.3) is separately estimated two times. ${ }^{6}$

The interest rate, the wage rate, and the business cycle serve as risk factors. The former two can be seen as the prices for the input factors capital and labour, while the latter is related to the output factor. For reasons of simplicity, we will only concentrate on the first two risk factors in this paper.

The number of employees is chosen as the firm characteristic determining the sensitivity to the wage rate, whereas short term debt, long term debt and the level of fixed assets are assumed to influence the interest rate sensitivity.

Table 1 contains a summary of the performance measures, the risk factors and the sensitivity determining firm characteristics to be used. Note that the explanatory variables, i.e. the firm characteristics and the risk factors, are the same for both regressions.

\section{Data}

In this section, we describe the data regarding the firm characteristics and exogenous factors used to estimate the model.

\footnotetext{
${ }^{5}$ The literature considers labour, capital and land as classical economic "factors of production", see a.o. Varian [15, p. 172].

${ }^{6}$ Elliott and Uphoff [4] as well as Wild [17] examine a similar system of relations. However, important differences with our approach are that, firstly, we concentrate on sensitivities to risk factors, and secondly, we try to explain sensitivities by firm characteristics. In the Wild, and Elliott and Uphoff papers sensitivities are not explained but only measured, assuming that sensitivities are constant.
} 
Table 1

Risk factors and sensitivity determining firm characteristics. ${ }^{2}$

\begin{tabular}{lll}
\hline Perf. meas., $R_{n t}$ & Risk factor, $f_{i t}$ & Firm characteristics, $f c_{j n t}$ \\
\hline & Wage rate & Number of employees \\
Cash flow & & Short term debt \\
Wage costs & Interest rate & Long term debt \\
& & Fixed assets \\
\hline
\end{tabular}

${ }^{\mathrm{a}}$ The abbreviations $R_{n t}, f_{i t}$, and $f c_{j n t}$ correspond with those used in expression (3.3).

The unit of observation used in the data on firm characteristics is the industry average, averaged across firms in Dutch industry groups (about second digit SIC). The source of these data is the SFGO (financial statistics concerning large firms) of the Netherlands Central Bureau of Statistics. In these statistics, large is defined as having assets in excess of Dfl. 10 million. ${ }^{7}$ In this paper, data of 18 industrial groups were used covering the period from 1980 to 1989 and containing both the balance sheets and the profit and loss statements.

The exogenous factors are macro-economic quantities, which are observed once a year. Their source is the International Financial Statistics contained in the Yearbook 1989 of the International Monetary Fund.

\section{Results}

After substitution of the variables mentioned in table 1 , we estimated expression (3.3) using Ordinary Least Squares. However, two adaptations were made. Firstly, we introduced an industry dummy for the wage rate sensitivity. Details about this dummy can be found in section 7. Secondly, after OLSregression of expression (3.3), we tested the hypotheses that autocorrelation, and heteroscedasticity across industries were absent. The test results indicated that both hypotheses had to be rejected. As a result, a correction procedure for autocorrelation and heteroscedasticity was applied, after which expression (3.3) was re-estimated. The estimation results of this second run are contained in table 2 . This table presents the influence of the firm characteristics on the sensitivities to the wage rate and the interest rate.

In order to clarify the meaning of the estimates presented in table 2, let us examine the influence of the number of employees on the wage rate sensitivity of the cash flow. This estimate, with a negative value of -4.114 , implies that the more employees, the more the cash flow will decrease in case of an increase in the wage rate.

Table 3 contains some average characteristics over the period 1980-1989 of the Basic Metal and the Crude Petroleum Industry. Combining the results from

${ }^{7}$ Dfl. stands for Dutch guilders. Dfl. 1.60 is about $\$ 1.00$. 
Table 2

The influence of the firm characteristics on the sensitivities.

\begin{tabular}{lllr}
\hline & & \multicolumn{2}{l}{ Influence on the sensitivity } \\
\cline { 3 - 4 } Risk factor & Sensitivity determining & Cash flow & \multirow{2}{*}{ Wage costs } \\
\hline Wage rate & Number of employees & -4.114 & 5.817 \\
Interest rate & Short term debt & -0.044 & -0.032 \\
& Long term debt & 0.013 & -0.017 \\
& Fixed assets & -0.004 & 0.015 \\
\hline
\end{tabular}

table 2 and table 3 , the sensitivities of the different industry groups can be computed using expression (3.4).

For example, let us assume that we want to calculate the sensitivity of the cash flow of the Basic Metal Industry to a change in the interest rate. The influence of short term debt, long term debt and the level of fixed assets on the interest rate sensitivity of the cash flow is $-0.044,0.013$ and -0.004 respectively. The current levels of short term debt, long term debt, and fixed assets in the Basic Metal Industry are 30.75, 134.40 and 210.45 . Hence, the interest rate sensitivity of the cash flow equals $-0.044 * 30.75+0.013 * 134.40-0.004 * 210.45=-0.5678$. This number implies that if the interest rate increases with $1 \%$, the cash flow decreases with Dfl. 567800 .-, which is about two percent of the total average cash flow of Dfl. 26 million.

In the same way the other sensitivities can be calculated. ${ }^{8}$ In order to be able to compare the sensitivities of the different industries with each other they are normalized by dividing them by their respective cash flows. To illustrate, in the case of the Basic Metal Industry the normalized sensitivity of the cash flow to a change in the wage rate is $-0.4151 / 26.2150=-0.0158$. The normalized as well as the non-normalized sensitivities of the cash flow are shown in table 4.

Figure 1 presents a plot of the wage rate ( $x$-axis) and interest rate ( $y$-axis) sensitivity of some industries in the Netherlands. From fig. 1, it can be seen at a single glance, that, for instance, the electrical engineering industry, EE, is most sensitive to a change in the wage rate and the interest rate.

\section{Interfirm comparison}

In this section, we describe how the estimated sensitivities can be used for interfirm comparison. Differences in sensitivities between firms may be partly

\footnotetext{
${ }^{8}$ As mentioned before, with respect to the wage rate, also an industry specific dummy was estimated. The estimated dummies for the Basic Metal Industry and Crude Petroleum Industry were 5.383 and 14.869. This dummy has to be taken account of when the wage rate sensitivity is computed. For example, the wage rate sensitivity of the Basic Metal Industry is $(5.383+-4.114 * 1.4095)=-0.4151$, see also section 7.
} 
Table 3

Some characteristics of the Basic Metal and Crude Petroleum Industry.

\begin{tabular}{lcc}
\hline Firm characteristics $^{\mathrm{a}}$ & Basic Metal Industry & Crude Petroleum Ind. \\
\hline Number of employees & 1.4095 & 1.0392 \\
Sales & 377.5785 & 2459.1320 \\
Total assets & 372.0529 & 1052.2236 \\
Short term debt & 30.7507 & 32.5248 \\
Long term debt & 134.3954 & 363.5282 \\
Fixed assets & 210.4476 & 517.0895 \\
Cash flow & 26.2150 & 83.9182 \\
\hline
\end{tabular}

${ }^{a}$ The amounts are in millions of guilders, the numbers of employees in thousands.

explained by differences in firm characteristics and partly by other causes. Here, we present a methodology to determine which part can be explained by firm characteristics and which cannot.

We will start from expression (2.3) concerning the relation between the sensitivities and the firm characteristics. This expression left no room for a firm specific deviation of the sensitivity given the firm characteristics. We will now relax this restriction and assume that the constant term $\gamma_{0 i}$ may vary across firms, while maintaining the assumption that the effect of the firm characteristics on the sensitivity is the same for all firms, i.e. $\gamma_{j i}, j=1, \ldots, m$, is the same for all firms. Mathematically, we assume that

$$
\tilde{b}_{i n t}=\gamma_{0 i}+\delta_{0 n i}+f c_{1 n t} \cdot \gamma_{1 i}+\ldots+f c_{m n t} \cdot \gamma_{m i}+\tilde{\eta}_{i n t} \quad i=1, \ldots, k, t=1, \ldots, T .
$$

In this relation, $\delta_{0 n i}$ should be interpreted as a firm specific deviation of the sensitivity. In this case the sensitivity can be split up in a systematic and an unsystematic part. The systematic part of the sensitivity consists of:

$$
\tilde{b}_{i n t}=\gamma_{0 i}+f c_{1 n t} \cdot \gamma_{1 i}+\ldots+f c_{m n t} \cdot \gamma_{m i}
$$

Table 4

\begin{tabular}{|c|c|c|}
\hline $\begin{array}{l}\text { Risk } \\
\text { factor }\end{array}$ & Basic Metal Ind. & Crude Pet. Ind. \\
\hline Wage rate & $\begin{array}{l}-0.0158 \\
(-0.4151)\end{array}$ & $\begin{array}{c}0.1262 \\
(10.5944)\end{array}$ \\
\hline Interest rate & $\begin{array}{c}-0.0217 \\
(-0.5678)\end{array}$ & $\begin{array}{c}0.0107 \\
(0.9007)\end{array}$ \\
\hline
\end{tabular}

The normalized sensitivities of the cash flow, the absolute sensitivities are in brackets. 


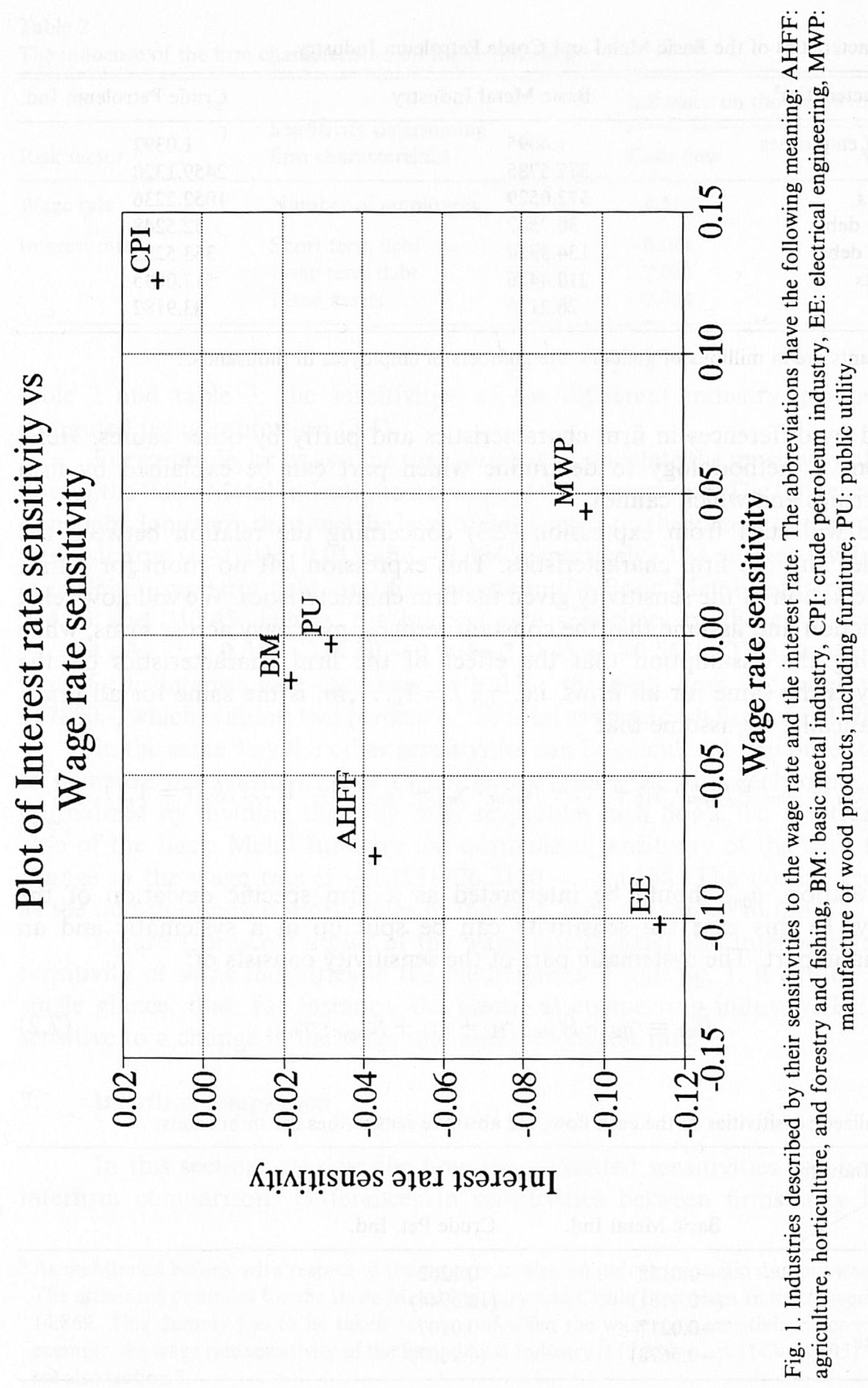


This part of the sensitivity is completely determined by firm characteristics. As a result, the impact of a change in a firm characteristic on the systematic part of the sensitivity can be predicted.

The unsystematic part is

$$
b_{i n t}^{*}=\delta_{0 n i}+\tilde{\eta}_{i n t}
$$

This part cannot be explained by the firm characteristics which are taken into account in the model. The following numerical example might be useful in order to clarify the issue. Suppose that we are interested in the wage rate sensitivity of the wage costs. Let us assume that the following relation holds between the wage rate sensitivity and the number of employees:

$$
w r s_{n, t}=\delta_{0 n}+\gamma_{0}+n e_{n, t-1} \cdot \gamma_{1}+\tilde{\eta}_{n t}
$$

The wage rate sensitivity of the $n$th firm at time $t$ equals a firm specific dummy $\delta_{0 n}$ plus a constant $\gamma_{0}$, which is the same for all firms, plus the product of the number of employees of the firm, denoted by $n e_{n, t-1}$ and the influence of the labour intensity on the wage rate sensitivity, $\gamma_{1}$.

Let us, furthermore, assume that the following relation between the wage costs and the wage rate sensitivity holds:

$$
\Delta W C_{n, t, t-1}=w r s_{n, t} \cdot \Delta w r_{t, t-1}+\tilde{\epsilon}_{n t}
$$

where $\Delta W C_{n, t, t-1}$ is the change in the wage costs of the $n$th firm between $t$ and $t-1$ and $\Delta w r_{t, t-1}$ is the change in wage rate ${ }^{9}$ between $t$ and $t-1$. Substitution of (7.4) into (7.5) leads to

$$
\Delta W C_{n, t, t-1}=\left(\delta_{0 n}+\gamma_{0}+n e_{n, t-1} \cdot \gamma_{1}\right) \cdot \Delta w r_{t, t-1}+\tilde{\nu}_{n t} \quad n=1, \ldots, N, t=1, \ldots, T .
$$

Estimation of this relation produces the following parameter estimates $\hat{\gamma}_{0}=-2.288$, $\hat{\gamma}_{1}=5.817$, the estimated values of the parameter $\hat{\delta}$ are -5.350 for the Basic Metal Industry and 0.527 for the Crude Petroleum Industry. ${ }^{10}$

The systematic relation between the number of employees and the wage rate sensitivity can be obtained by substituting the estimates of $\gamma$ into expression (7.4):

$$
w r s_{n, t}=-2.288+5.817 * n e_{n, t-1} \text {. }
$$

\footnotetext{
${ }^{9}$ Note that we refer here to the nation-wide wage rate and not to the specific wage rate of an individual firm.

${ }^{10}$ These results were also used in section 6 . As was mentioned before, the sensitivities to other risk factors, such as the interest rate and the business cycle, were also estimated. However, for reasons of simplicity, these sensitivities are left out of consideration in this section.
} 


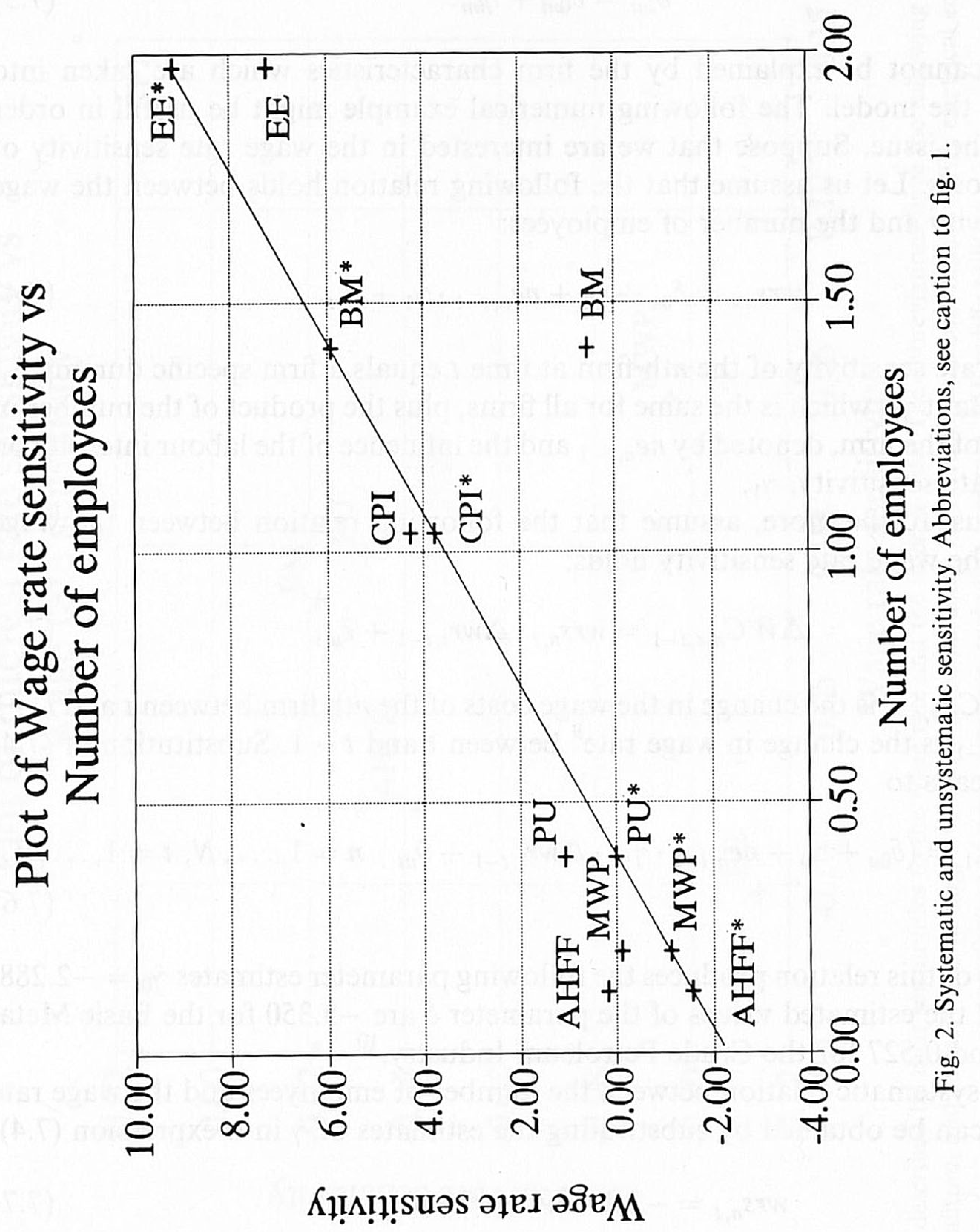


This line is drawn in fig. 2. The constant equals $\hat{\gamma}_{0}(-2.288)$, while the slope of the line equals $\hat{\gamma}_{1}$ (5.817). The average firms in the different industries are denoted by their abbreviations and are plotted according to the combination of their wage rate sensitivity and their number of employees. The vertical deviation of a firm from the line denoted by expression (7.7) denotes its unsystematic sensitivity, whereas the systematic sensitivity can be computed by substituting the number of employees of the firm into expression (7.7).

For example, let us examine the wage rate sensitivity of the Basic Metal Industry (BM). On average 1410 employees are working in the Basic Metal Industry. Hence, its systematic wage rate sensitivity, which is denoted by $\mathrm{BM}^{*}$, equals $(-2.288+5.817 * 1.410)=5.914$. Its measured unsystematic sensitivity is -5.350 , and as a consequence its resulting sensitivity is $(5.912-5.350)=0.564$.

In this example, $\mathrm{BM}^{*}$ can be seen as the sensitivity of a hypothetical industry with the same set of characteristics as the Basic Metal Industry. The negative unsystematic sensitivity of BM with value -5.350 will be preferred in case of an increase in the wage rate, in the opposite case a positive unsystematic sensitivity will be preferred.

In order to explain the unsystematic under-sensitivity, the average firm in the Basic Metal Industry has to be examined more closely. Firm characteristics must be found, which were not taken into account in the model, but which might explain the under-sensitivity. In this case, the under-sensitivity might be explained by the kind of employees used. For example, an industry might be less sensitive to the wage rate, because it has more temporary employees. Hence, in this case the results of the research lead to new questions concerning future research.

\section{Other applications of the risk profile}

In the previous sections, a method was presented to determine the sensitivities of a firm to unexpected changes of exogenous factors. We also showed an application to interfirm comparison. In this section, some other applications of the risk profile are mentioned.

First of all, the risk profile indicates the firm's current risk position. Insight into the strengths and weaknesses of the firm is gained by considering the relation between the cash flow and exogenous factors as expressed in the risk profile. In this way, a prospective view on the firm is developed. Questions like: "What happens with the cash flow if the interest rate increases by ten percent?" etc. can be answered in a straightforward manner. One simply has to multiply the change in the interest rate by its sensitivity in order to get the ceteris paribus change in cash flow.

In addition, the model relates sensitivities to firm characteristics. Hence, the impact of a change in firm characteristics on the risk profile is approximately known. This information can be useful for management, because most management decisions, such as investment decisions, imply a change in firm characteristics. 
Finally, banks can use the model for two purposes. First, to assess the risk profile of each individual firm, which information is useful for deciding on a loan application. Second, the model can be used to calculate the risk profile of their entire client portfolio, by adding and weighing the risk profile of the individual clients. In that case, the risks the bank is faced with can be determined.

\section{Tools to facilitate application of the model}

In this section, some tools are described which may facilitate the application of the model in practice.

In order to obtain a clear view on the issue, fig. 3 presents an input/output scheme of the method proposed in the preceding sections. The input of the model consists of firm characteristics of $N$ firms observed during $T$ years and the corresponding risk factor values during those years. The output of the model is the relation between the performance measure, the firm characteristics and the sensitivities to the exogenous factors. As an example of such a relation one might think of expression (7.7).

In accordance with expression (3.4), all information concerning this relation is contained in the matrix $\hat{\Gamma}$ with elements $\hat{\gamma}_{j i}$, denoting the sensitivity changing influence of the firm characteristics. This information is sufficient to compute the sensitivities of a firm by means of expression (3.4), if its firm characteristics are known.

In order to improve the insight into the influence of the sensitivities on the performance measure, the influence of fictitious unexpected changes of the exogenous factors on the performance measure can be calculated making use of the computed sensitivities.

These fictitious unexpected changes of the exogenous factors can be provided by another model. Figure 4 presents the scheme to be followed. First, the

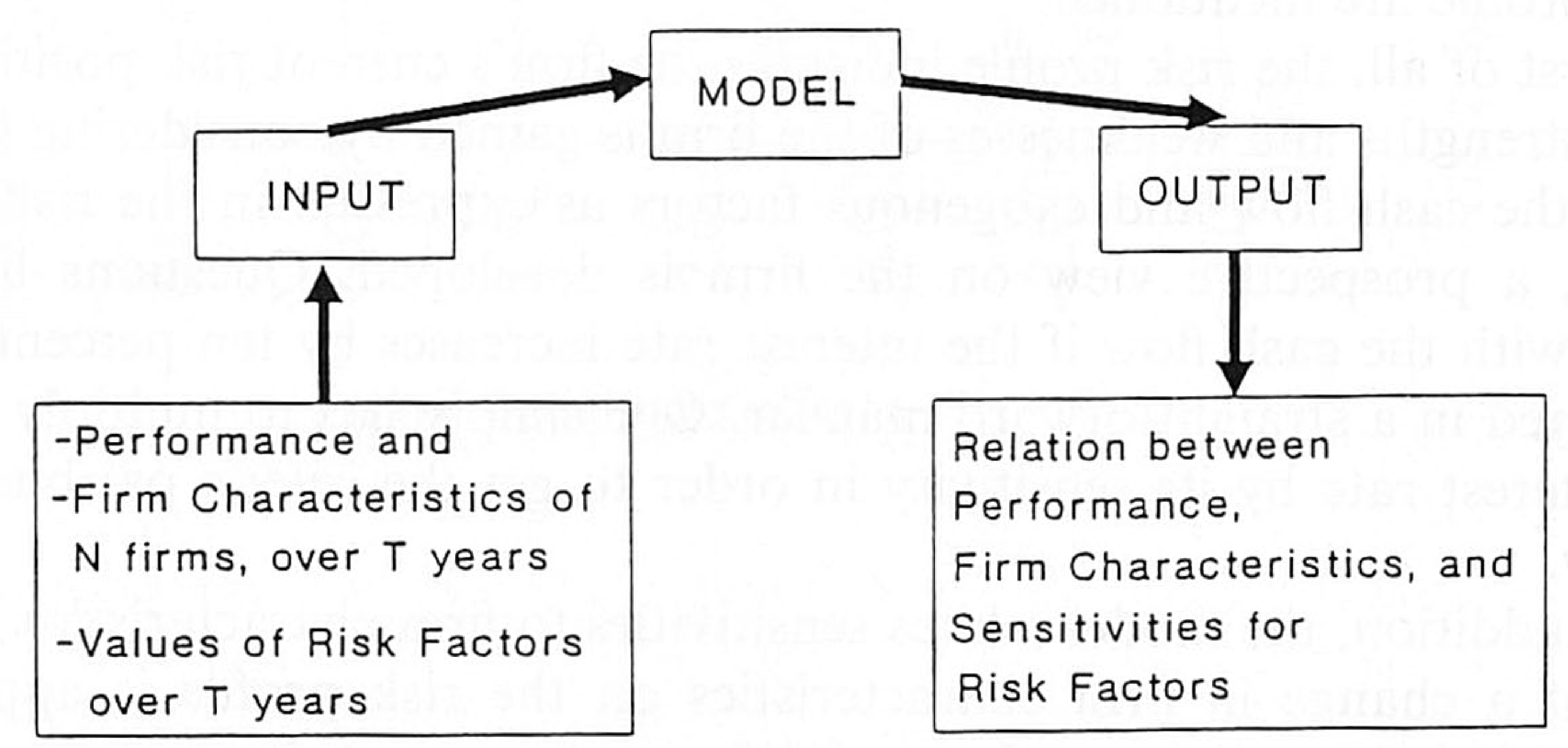

Fig. 3. Input/output scheme of the proposed method. 


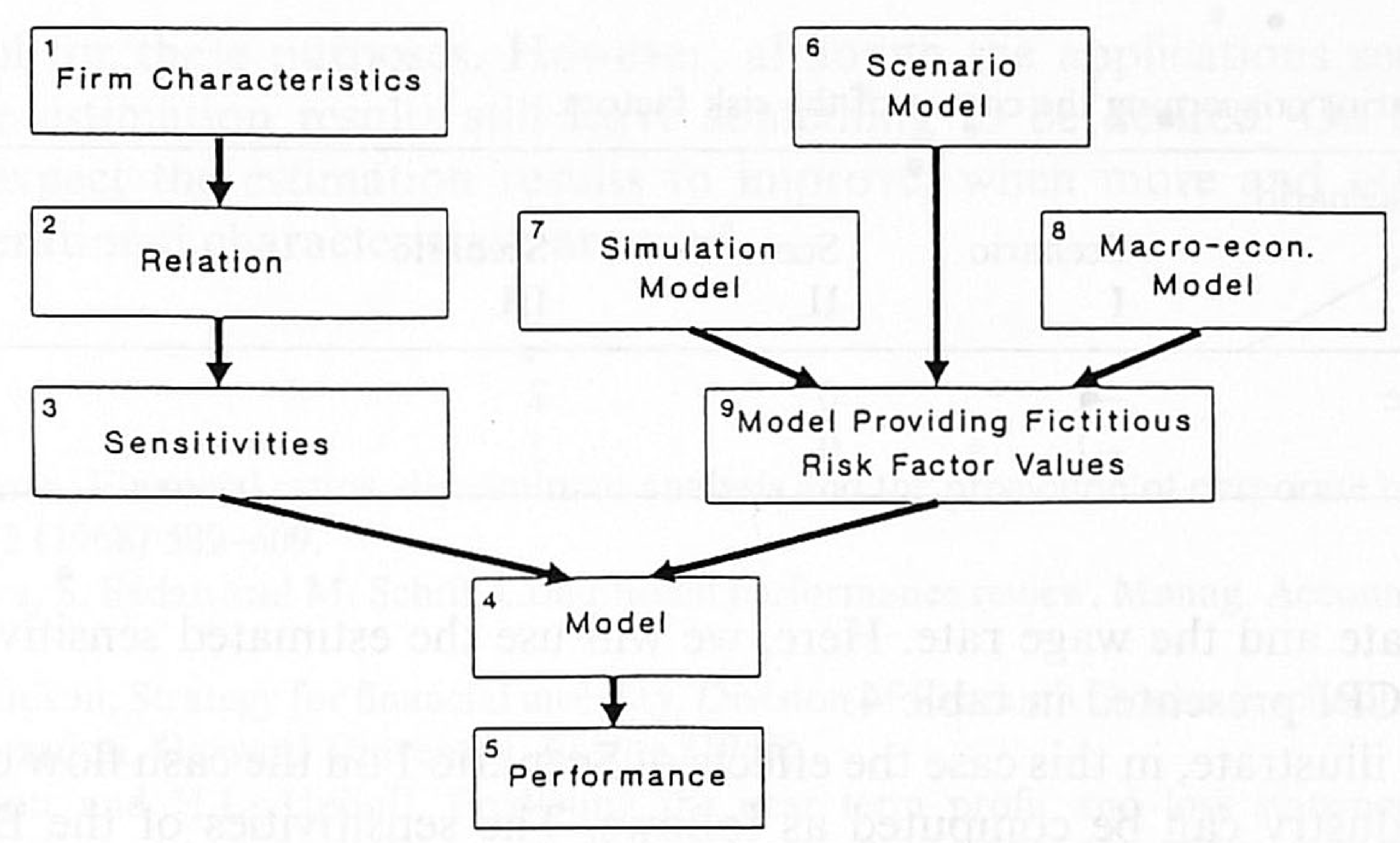

Fig. 4. Models generating fictitious factor values.

characteristics $^{11}$ of the firm under consideration (1), have to be substituted in the estimated relation (2), e.g. expression (3.4), in order to obtain its sensitivities (3). Next, a simple model (4) multiplies the sensitivities by the fictitious risk factor changes in order to obtain the change in performance measure (5). The fictitious factor changes are provided by another model (9), such as a scenario model (6), a simulation model (7), or a macro-econometric forecast model (8).

In the simulation model, fictitious changes of exogenous factors are drawn from an assumed probability density function. Given these changes, the corresponding change in performance measure is calculated. If this drawing procedure is repeated many times, then the probability density function of the performance measure can eventually be approximated by a frequency plot of the resulting values of the performance measure. This approach has been followed by Hertz $[6,7]$.

In the scenario model, the user provides only a number of coherent combinations of changes of exogenous factors and computes the corresponding change in performance measure.

A macro-econometric forecast model predicts future values of economic variables. These predictions can be substituted in the model, after which the resulting performance measures can be computed. Macro-econometric forecast models are used by a.o. banks and large corporations.

It will now be shown how a scenario model can be used in combination with the estimated sensitivities in order to compute the corresponding change in cash flow. Assume that the effects of the scenarios presented in table 5 have to be computed. Each scenario provides some possible outcomes for the changes of the

\footnotetext{
${ }^{11}$ The numbers in parentheses correspond with the numbers in fig. 4.
} 
Table 5

Three scenarios concerning the course of the risk factors.

\begin{tabular}{|c|c|c|c|}
\hline $\begin{array}{l}\text { Risk } \\
\text { factor }\end{array}$ & $\begin{array}{l}\text { Scenario } \\
\text { I }\end{array}$ & $\begin{array}{l}\text { Scenario } \\
\text { II }\end{array}$ & $\begin{array}{l}\text { Scenario } \\
\text { III }\end{array}$ \\
\hline Interest rate & -1 & 0 & 2 \\
\hline Wage rate & -1 & 0 & 3 \\
\hline
\end{tabular}

interest rate and the wage rate. Here, we will use the estimated sensitivities of the $\mathrm{BM}$ and CPI presented in table 4.

To illustrate, in this case the effects of Scenario I on the cash flow of the Basic Metal Industry can be computed as follows. The sensitivities of the Basic Metal Industry to a change in the wage rate and the interest rate are -0.4151 and -0.5678 respectively. As a result, the change in cash flow in case of Scenario I is $-0.4151 *(-1)+-0.5678 *(-1)=0.9829$ (being Dfl. 982900.-), implying an increase in the cash flow of about $4 \%$.

In the same way, the resulting cash flows in the five other cases can be computed. Table 6 presents the results of these calculations. Scenario I turns out to be favorable for the Basic Metal Industry, whilst Scenario III is better for the Crude Petroleum Industry.

\section{Conclusion}

In the foregoing we described a new method to evaluate firms on the basis of their risk profiles. The proposed method combines firm characteristics and exogenous factors in order to determine the risk profile of the firm. The risk profile is a vector containing sensitivities of the variable of interest - in our case the cash flow - to risk factors. The sensitivities are assumed to be explained by firm characteristics.

In this paper, we also showed some practical applications of the model making use of empirical results obtained with real data. More specifically, its use for interfirm comparison and scenario analysis was described. The model appeared

Table 6

The change in cash flow for the different scenarios.

\begin{tabular}{lrll} 
Industry & Scenario & $\begin{array}{l}\text { Scenario } \\
\text { II }\end{array}$ & $\begin{array}{l}\text { Scenario } \\
\text { III }\end{array}$ \\
\hline Basic Metal Ind. & 0.9829 & 0 & -2.5336 \\
Crude Pet. Ind. & -11.4951 & 0 & 23.8909 \\
\hline
\end{tabular}


to be useful for these purposes. However, although the applications seem to be fruitful, the estimation results still leave something to be desired. On the other hand, we expect the estimation results to improve, when more and other data, such as operational characteristics, are used.

\section{References}

[1] E.I. Altman, Financial ratios, discriminant analysis and the prediction of corporate bankruptcy, J. Fin. 23 (1968) 589-609.

[2] A. Barnea, S. Sadan and M. Schiff, Conditional performance review, Manag. Accounting (1975) 19-22.

[3] G. Donaldson, Strategy for financial mobility, Division of Research Graduate school of Business Administration, Harvard University, Boston (1969).

[4] J.W. Eliott and H.L. Uphoff, Predicting the near term profit and loss statement with an econometric model: A feasibility study, J. Accounting Res. (1972) 259-274.

[5] G. Foster, Financial Statement Analysis (Prentice-Hall, Englewood Cliffs, 1978).

[6] D.B. Hertz, Risk analysis in capital investment, Harvard Bus. Rev. (1964) 95-106.

[7] D.B. Hertz, Investment policies that pay off, Harvard Bus. Rev. (1968) 96-108.

[8] C. Hsiao, Analysis of Panel Data (Cambridge University Press, Cambridge, 1986).

[9] B. Lev, Financial Statement Analysis: A New Approach (Prentice-Hall, Englewood Cliffs, NJ, 1974) pp. 149-151.

[10] B. Lev, On the use of index models in analytical reviews by auditors, J. Accounting Res. 18 (1980) 524-550.

[11] B. Rosenberg and W. McKibben, The prediction of systematic and specific risk in common stocks, J. Fin. Quantit. Anal. (1973) 317-333.

[12] J. Spronk and D. van der Wijst, A multi-factor framework for firm evaluation, in: Finance and Investment, State of the Art 1987, eds. W.G. Hallerbach, F.C.J. Bemelman, J.W.R. Schuit and P.J. van Mierlo (Erasmus University Rotterdam, 1987) pp. 317-330.

[13] Spronk, J. and D. van der Wijst, Determinants of financial structure in retailing, Research Paper 8801, Research Institute for Small and Medium-Sized Business in Zoetermeer, The Netherlands (1988).

[14] W. Van Gremsbergen, De raming van het systematisch risico voor Belgische Ondernemingen, Tijdschrift voor Economie en Management 25 (1980) 519-545.

[15] H.R. Varian, Microeconomic Analysis, 2nd ed. (W.W. Norton \& Co., 500 Fifth Avenue, New York, NY 10110, 1984).

[16] D. van der Wijst, Modelling interfirm comparisons in small business, Omega 18 (1990) 123-129.

[17] J.J. Wild, The prediction performance of a structural model of accounting numbers, J. Accounting Res. 25 (1987) 139-160. 